\section{Oesophageal Cancer in China}

The epidemiology of oesophageal carcinoma is a fascinating and enigmatic problem. There is no other tumour with such large variations in incidence in different parts of the world, ${ }^{1}$ and there are often sharp gradients in frequency over short distances. ${ }^{2}$ Despite these features the aetiology remains obscure. An association with alcohol has been established in many parts of the world, such as the high-incidence areas in Brittany and Normandy, ${ }^{3}$ but there is no direct relationship with the amount of alcohol consumed. This has led to suggestions that contaminants of alcohol, or specific types of alcoholic beverage, may be incriminated in the high-incidence areas of Africa. ${ }^{2}$ Yet the high frequency of oesophageal cancer in Iran and the U.S.S.R. around the Caspian sea occurs in a predominantly Moslem population and cannot be related to any type of alcohol consumption. ${ }^{4}$ In Johannesburg, South Africa, tobacco smoking appears to have a stronger association than alcohol. ${ }^{5}$

Oesophageal cancer is common in parts of China, and a group of workers have recently reported details of an epidemiological study there. ${ }^{6}$ It is interesting not only for the light shed on the aetiology of the tumour but also because it gives some insight into the Chinese approach to research of this kind.

The studies started in 1959 in Linhsien, in Honan Province of northern China, where the "dysphagia syndrome" was known to be endemic. After preliminary studies had confirmed that the syndrome was due to carcinoma of the oesophagus a wider programme was undertaken covering large parts of the three northern provinces in which the Taihang mountains are a dominant geographical feature. In the words of the report in Scientia Sirica: "this was made possible by having the full co-operation of the administrative authorities and by mobilising the masses of the people"-no small task for an area with approximately 50 million inhabitants. Mass meetings were held to obtain the co-operation of the people in answering questionnaires or attending for medical examination. An important part of the study was the use of cytology for the confirmation of diagnosis in clinical cases and for the detection of preclinical or precancerous lesions. ${ }^{7}$ A mass survey of 11654 people over the age of 30 found 136 cases of cancer of which 96 were "early." In the main study $66 \%$ of the cases were diagnosed by barium swallow and $6 \%$ by histology or cytology. Clinical cases were included only if very strict criteria were met in the patient's symptomatology. While purists may cavil at such a low histological confirmation experience elsewhere has shown that greater errors may be introduced into cancer rates by the exclusion of clinical cases, ${ }^{8}$ particularly as the final clinical picture of oesophageal cancer is very characteristic. The highest rates, adjusted for age and sex, were found in Yangeheng County and Hehpih, with respective figures of 135 and 139 per 100000 ; the lowest rates were in Hunyuan County ( 1.4 per 100000$)$, giving differences between the high- and low-incidence areas of nearly 100 fold. Statistics over a 30-year period in Linhsien County showed a uniform stable mortality rate, suggesting that the responsible agents were a long standing and integral part of the human environment. Detailed geographical studies showed the highest rates in the southern part of the Taihang mountain range; there was a decreasing mortality extending out in concentric belts with low rates in the south and in the Peking area. During the investigations it was found that there was also a high prevalence of pharyngeal-oesophageal cancer in domestic fowls in the high incidence areas, with a ratio of $9: 1$ between areas of high and low incidence.

A variety of environmental factors were investigated by the research group, and there are brief reports of some experimental work in animals. Thin layer chromatography showed that food items from the high-incidence areas contained nitrosamine compounds in $23 \%$ of samples tested, whereas such compounds were only found in $1.2 \%$ of foodstuffs from low-incidence areas. Mass spectrometry showed higher levels of secondary amines and nitrites in Linhsien county than in a control area. Trace elements were estimated in the foodstuffs and water from different areas, and the most striking feature was the low concentration of molybdenum in high-incidence areas.

The possible role of nitrosamines in the genesis of oesophageal carcinoma has been suggested by Magee and Barnes ${ }^{9}$ and McGlashan et al. ${ }^{10}$ It has also been postulated that molybdenum deficiency in plants may result in the formation of nitrosamines from nitrates and secondary amines $;^{11}$ but nitrosamines were not detected in samples of beer and other drinks from high-incidence areas of East Africa. ${ }^{2}$ Though the high-incidence areas around the Caspian sea appear to be associated with particular ecological conditions no specific agent has yet been identified as an aetiological factor. ${ }^{12}$ The Chinese workers sum up the present situation by concluding that the aetiology of oesophageal carcinoma is a complex and multifactorial problem. Their own contributions may well extend further our understanding of this distressing form of cancer.

1 Doll, R., 1967, Prevention of Cancer: Pointers from Epidemiology. London, Nuffield Provincial Hospitals Trust.

${ }^{2}$ Cook, P., British fournal of Cancer, 1971, 25, 853.

3 Tuyns, A. J., and Masse, G., International fournal of Epidemiology, 1975, $4,55$.

${ }^{4}$ Kmet, J., and Mahboubi, E., Science, 1972, 175, 846.

5 Bradshaw, E., and Schonland, M., British fournal of Cancer, 1974, 30, 157.

- Coordinating Group for Research on the Etiology of Esophageal Cancer in North China, Scientia Sinica, 1975, 18, 131.

${ }^{7}$ Coordinating Group for Research on the Etiology of Esophageal Cancer in North China. Scientia Sinica, 1973, 16, 457.

${ }^{8}$ Burkitt, D. P., Hutt, M. S. R., and Slavin, G., British fournal of Cancer, 1966, 22, 1.

Magee, P. N., and Barnes, J. M., Advances in Cancer Research, 1967, 10, 163.

${ }^{10}$ McGlashan, N. D., Walters, C. L., and McClean, A. E. M., Lancet, 1968, 2, 1017.

${ }^{11}$ Burrell, R. J. W., Roach, W. A., and Shadwell, A., Fournal of the National Cancer Institute, 1966, 36, 201.

12 Mahboubi, E., et al., British fournal of Cancer, 1973, 28, 197.

\section{Gastric Ulcer-Short-term Healing and Long-term Response}

Undoubtedly gastric ulcer healing can be accelerated by traditional treatment by bed rest, and by the use of liquorice derivatives, especially carbenoxolone sodium. ${ }^{1}$ In addition, there is some evidence that short-term healing may be speeded by a variety of other drugs including anticholinergic agents, ${ }^{2}$ antipepsins, ${ }^{3}$ bismuth chelates, ${ }^{4}$ metaclopramide, ${ }^{5}$ and substituted prostaglandins (which are powerful hyposecretory agents). ${ }^{6}$ The mechanisms by which ulcer healing can be induced are, however, less certain - as is the long-term value of medical treatment. 
Much attention has been given to the mechanisms of action of carbenoxolone, and a number of effects have been described. These include some antipeptic activity, ${ }^{78}$ a tendency to induce mucosal glycoprotein synthesis, ${ }^{9}$ and a tendency to prolong the lifespan of epithelial mucosal cells. ${ }^{10}$ In addition the drug protects the mucosa against two actions commonly considered to be harmful: the ability of bile in the stomach to induce back diffusion of acid into the mucosa, ${ }^{11}$ and the tendency of aspirin to cause a lowering of the electrical potential difference across the gastric mucosa. ${ }^{12}$ Some of these actions are probably natural consequences of each other, but as yet there is no means of judging which are of primary importance nor whether any particular action is of special significance in the ulcer-healing process.

Though the efficacy of short-term ulcer treatment can be clearly shown, it may be unfair to assume that the results of treatment in one place will be mirrored by those obtained elsewhere, and it would certainly be unreasonable to assume that short-term treatment will also influence long-term outcome. In clinical trials conducted in the United Kingdom effective short-term treatment seems to result in healing in four to six weeks of approximately $40 \%$ of all ulcers. ${ }^{13} 14$ Higher healing rates have been obtained elsewhere: in Australia and in the Veterans treatment trial in the U.S.A. some two-thirds of all ulcers healed during a six-week inpatient treatment period. ${ }^{1516}$ Neither of these groups of patients received any of the newer antiulcer drugs. The difference from the results obtained in treatment trials here may reflect referral and selection factors: thus many ulcers, perhaps as many as a quarter of those referred for treatment, can heal spontaneously without any intervention at all, and any scheme which results in early treatment will, therefore, include the spontaneous healers and thus apparently improve treatment responses.

A point of far greater importance to the clinician is the tendency for all gastric ulcers to relapse. Simple consideration of the fate of patients initially treated medically has shown that from a quarter to over a third of all such patients have a stomach operation in succeeding years. ${ }^{1718}$ Even so, these patients form a selected group and the outcome seems to be worse if all ulcer patients are taken together. A recent survey ${ }^{19}$ conducted in the Aberdeen area showed that of the total of 151 patients diagnosed as having gastric ulcers in 1967 no fewer than 69 were ultimately operated upon; and of the medically managed group of 82 only 44 remained entirely free of symptoms after treatment.

At present we know virtually nothing about factors which predispose to relapse or about means of preventing relapse. The U.S. Veterans study suggested that gastric ulcer with coexistent duodenal ulcer was especially likely to relapse ${ }^{21}$ and (somewhat unsurprisingly) that ulcers which failed to heal during short-term treatment were especially likely to give further trouble. ${ }^{16}$ Relapse has been said to be more frequent in the young than in the old and in men than in women, ${ }^{22} 23$ but the Veterans study showed no effect of age, nor that initial ulcer size or site were important determinants of recurrence. ${ }^{20}$

Clinical attempts to prevent recurrence have largerly depended upon advice about stopping smoking, avoiding so-called ulcerogenic drugs, and getting regular meals. Sensible as this advice may seem it has little or no practical justification. Little is known about the value of maintenance drug treatment. A limited trial in Australia suggested that an anticholinergic drug, glycopyrronium, when given in maximum doses could reduce relapse rates. There has also been a suggestion that maintenance therapy with carbenoxolone prevented recurrence in South African patients, ${ }^{1}$ but the dose used, at least in the
United Kingdom, produces side effects of fluid retention so frequently that long-continued treatment seems unwise. As matters stand, it is hard to gainsay the surgeon who argues that relapse after a good course of medical treatment is a fair indication to consider operation.

\footnotetext{
1 Bank, S., and Marks, I. N., Clinics in Gastroenterology, 1973, 2, 379. Baume, P. E., Hunt, J. H., and Piper, D. W., Gastroenterology, 1972, 63, 399.

3 Zimmon, D. S., et al., Gastroenterology, 1969, 56, 19.

4 Boyes, B. E., et al., Gut, 1974, 15, 833.

5 Hoskins, E. O. L., Postgraduate Medical fournal, 1973, 48, 95.

${ }^{6}$ Fung, W. P., Karim, S. M. M., and Tye, C. Y., Lancet, 1974, 2, 10.

Berstad, A., Scandinavian fournal of Gastroenterology, 1972, 7, 129

${ }^{8}$ Roberts, N.' B., and Taylor, W. H., Clinical Science and Molecular Medicine, 1973, 45, 213 .

Shillingford, J. S., Lindup, W. E., and Parke, D. V., Biochemical Society Transactions, 1974, 2, 1104.

10 Lipkin, M., Gut, 1971, 12, 599.

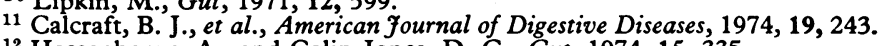

12 Hossenbocus, A., and Colin-Jones, D. G., Gut, 1974, 15, 335.

13 Doll, R., et al., Lancet, 1962, 2, 793.

14 Turpie, A. G. G., Runcie, J., and Thomson, T. J., Gut, 1969, 10, 299.

Herrmann, R. P., and Piper, D. W., American fournal of Digestive Diseases, $1973,18,1$.

${ }_{16}$ Sun, D. C. H., and Stempien, S. J., Gastroenterology, 1971, 61, 576.

17 Swynnerton, B. F., and Tanner, N. C., British Medical fournal, 1953, 2,

18 Ihre, B. J. E., Barr, H., and Havermark, G., Gastroenterologia, 1964, 102,

19 Mowat, N. A. G., Needham, C. D., and Brunt, P. W.,Quarterly fournal of Medicine, 1975, 44, 45.

${ }^{20}$ Hanscom, D. H., and Buchman, E., Gastroenterology, 1971, 61, 585.

21 Rumball, J. M., Gastroenterology, 1971, 61, 622.

22 Flood, G. A., and Hennig, G. C., Gastroenterology, 1950, 16, 57

${ }^{23}$ Krag, E., Acta Medica Scandinavica, 1966, 180, 657
}

\section{Local Renal Hypothermia}

Surgery on a kidney with sufficient residual nephrons to be worthy of conservation is limited by one main factor: the additional damage to renal tissue caused by the operative procedure. Haemorrhage from the cut surface of the kidney impairs the field of view and is apt to lead to some degree of inaccuracy, too speedy surgery, and a limited standard of delicacy in handling the organ. Control of haemorrhage is relatively easy by the use of a pedicle clamp, but this in turn introduces a risk to the nephrons from ischaemia.

In $1956 \mathrm{Semb}^{1}$ first described the use of hypothermia to prolong the ischaemic time of a kidney during operation. He claimed, on the basis of previous experiments in animals, ${ }^{2}$ that local hypothermia could double the safe ischaemic time. He advocated the use of hypothermia produced by plastic bags filled with ice in the operation of partial nephrectomy, but in fact he had used hypothermia only three times in 226 reported cases. In 1960 Hamilton Stewart ${ }^{3}$ reported 41 cases of conservative renal surgery in which he had reduced the renal temperature to $21^{\circ} \mathrm{C}$, and he stated that hypothermia was indicated where the renal procedure was likely to require more than 12 minutes ischaemia. He assessed all his cases postoperatively by intravenous pyelography and claimed that pyelographic function in all cases was unimpaired. He warned, however, that pockets of air between the cooling bags and the surface of the kidney could insulate the kidney and consequently fail to give the necessary hypothermia, and he suggested that the probe should be moved to various parts of the kidney to assess the average lowering of temperature. Secondly, he noted that a further fall of temperature could occur after the cooling bags had been removed, and in view of this he suggested removal of the cooling bags when the temperature reached $23^{\circ} \mathrm{C}$; presumably some parts of the kidney were already at a lower temperature, which diffused subsequently through the whole organ. 